\title{
Correction to: Physalin A induces G2/M phase cell cycle arrest in human non-small cell lung cancer cells: involvement of the p38 MAPK/ROS pathway
}

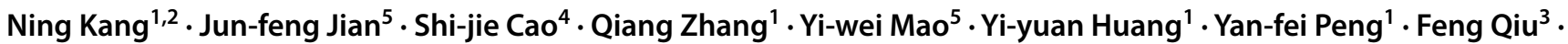 \\ Xiu-mei Gao ${ }^{2}$
}

Published online: 2 December 2021

(c) Springer Science+Business Media, LLC, part of Springer Nature 2021

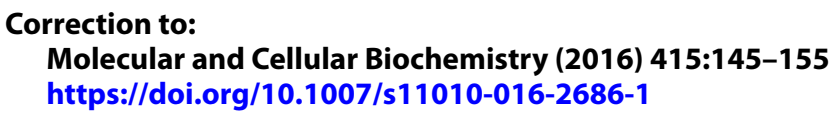

In the original publication of the article, Fig. $1 \mathrm{C}$ was published incorrectly. The correct version of Fig. 1 is provided in this correction.

Feng Qiu

fengqiu20070118@163.com

$\triangle$ Xiu-mei Gao

gaoxiumei@tjutcm.edu.cn

1 School of Integrative Medicine, Tianjin University of Traditional Chinese Medicine, 312 Anshanxi Road, Nankai District, Tianjin 300193, People's Republic of China

2 Tianjin State Key Laboratory of Modern Chinese Medicine, Tianjin University of Traditional Chinese Medicine, 312 Anshanxi Road, Nankai District, Tianjin 300193, People's Republic of China

3 College of Traditional Chinese Medicine, Tianjin University of Traditional Chinese Medicine, 312 Anshanxi Road, Nankai District, Tianjin 300193, People's Republic of China

4 Department of Natural Products Chemistry, Shenyang Pharmaceutical University, 103 Wenhua Road, Shenyang 110016, People's Republic of China

5 Department of Biochemistry and Molecular Biology, Shenyang Pharmaceutical University, 103 Wenhua Road, Shenyang 110016, People's Republic of China 


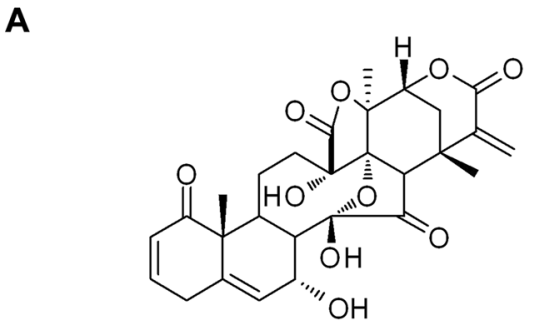

B

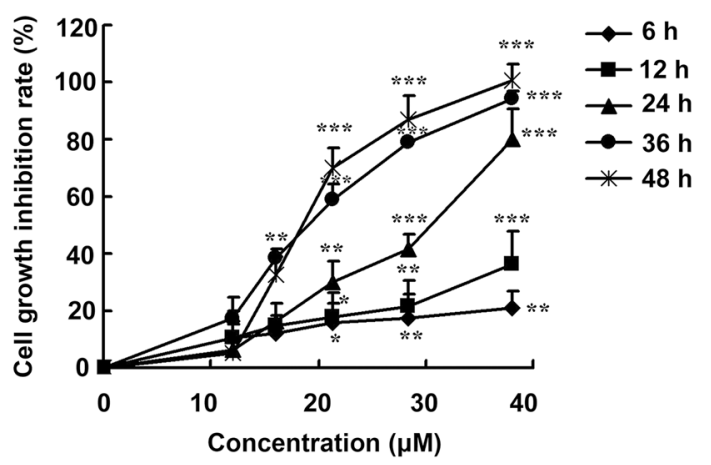

C
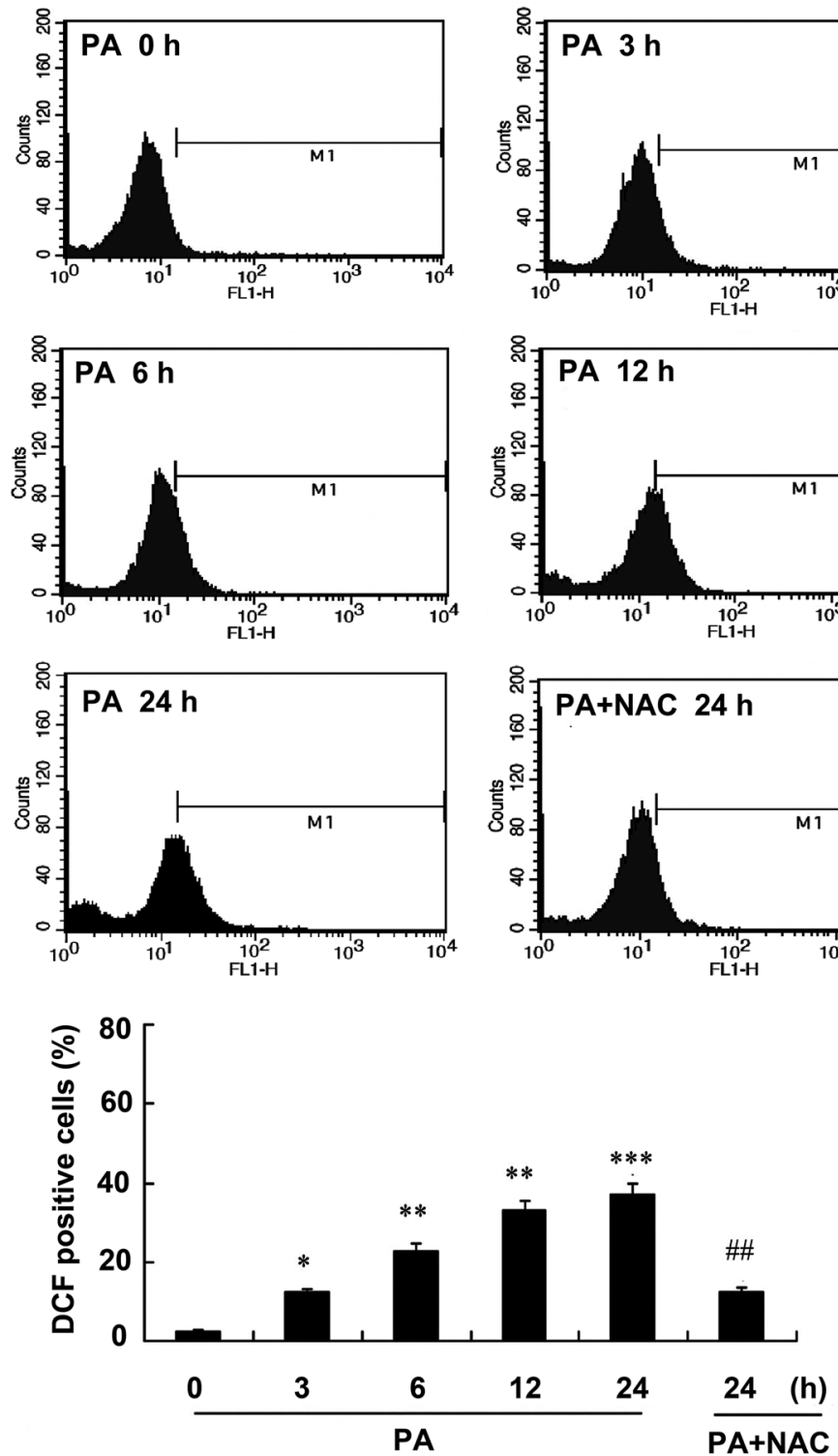

Fig. 1 Physalin A (PA) induced growth inhibition and reactive oxygen species (ROS) generation in human non-small-cell lung cancer A549 cell. A Chemical structure of PA. B A549 cells were treated with various doses $(0,12,16,21.3,28.4$, and $38 \mu \mathrm{M})$ of PA for 3,6 , 12 , and $24 \mathrm{~h}$. Cell growth inhibition rate (\%) was measured using the MTT assay. Data are shown as mean \pm standard deviation (SD) from three independent experiments. $* P<0.05, * * P<0.01$, $* * * P<0.001$ versus controls $(0 \mu \mathrm{M}$ PA) at the same time point. C A549 cells were
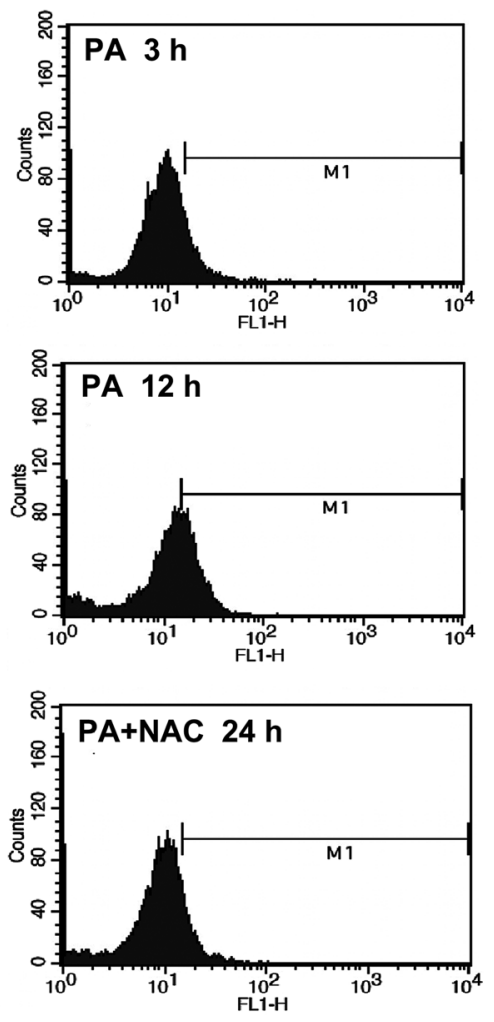

PA+NAC

Publisher's Note Springer Nature remains neutral with regard to jurisdictional claims in published maps and institutional affiliations.

cultured with $28.4 \mu \mathrm{M}$ PA for $0,3,6,12$, and $24 \mathrm{~h}$ in the absence or presence of $3 \mathrm{mM} \mathrm{N}$-acetylcysteine (NAC), the ROS scavenger. The generation of ROS was measured by flow cytometry using the ROSdetecting fluorescent dye DCF-DA. Data are shown as mean \pm SD from three independent experiments. $* P<0.05, * * P<0.01$, and $* * * P<0.001$ versus control group $(28.4 \mu \mathrm{M}$ PA for $0 \mathrm{~h}) ;{ }^{\# \#} \mathrm{P}<0.01$ versus A549 cells treated with $28.4 \mu \mathrm{M}$ PA for $24 \mathrm{~h}$ 